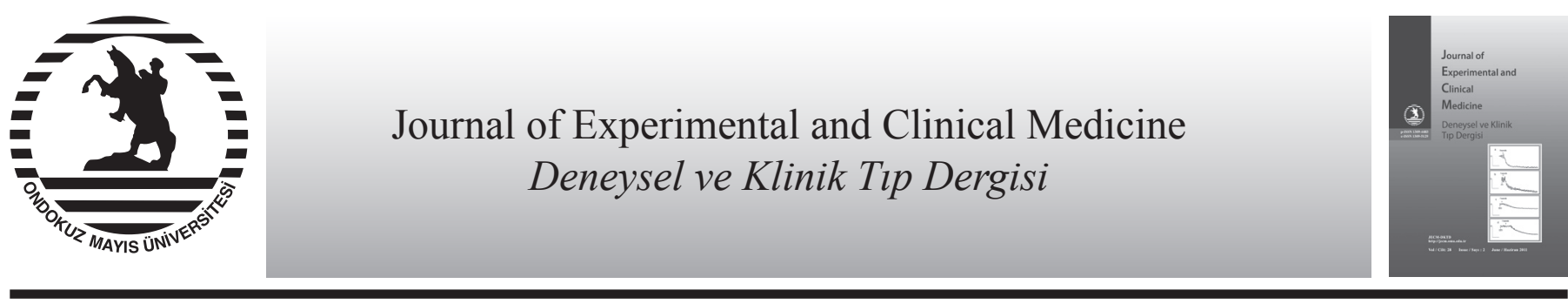

Olgu Sunumu / Case Report

\title{
Fleksör pollisis longus tendonunun kas tendon bileşkesinden açık travmatik avulsiyonu
}

\author{
An exceptionally infrequent case report open traumatic avulsion of flexor pollicis longus muscle tendon from muscle \\ tendon joint
}

Umut Tuncel

Gaziosmanpaşa Üniversitesi, Tıp Fakültesi, Plastik Rekonstrüktif ve Estetik Cerrahi AD, Tokat

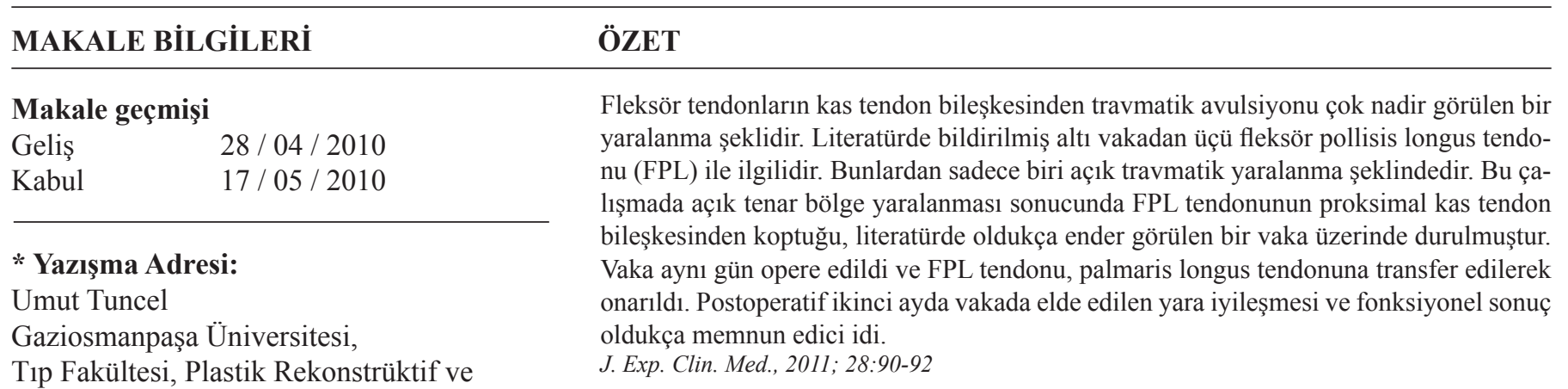

Estetik Cerrahi AD, Tokat

e-posta: drumuttuncel@gmail.com

\section{Anahtar Kelimeler: \\ Tendonlar \\ Tendon yaralanmaları \\ Tendon transferi \\ Palmaris longus \\ El yaralanmaları \\ Kas tendon bileşkesi}

\begin{abstract}
The traumatic avulsion of flexor tendons from muscle tendon joint is an exceptionally infrequent form of injury. Three of six cases that are reported in medical literature are related to flexor pollicis longus (FPL) tendon. Only one of them is in the form of open traumatic injury. Current report present exceptionally infrequent case in medical literature, in which FPL tendon ruptured from proximal muscle tendon junction after an open tenar area injury. Patient was operated at the same day and FPL tendon was repaired with transferring to the palmaris longus tendon. Wound healing and functional result at second month postoperatively were satisfying.

J. Exp. Clin. Med., 2011; 28:90-92
\end{abstract}

Keywords:

Tendons

Tendon Injuries

Tendon Transfer

Palmaris longus

Hand injuries

Musculotendinous junction

C 2011 OMU All rights reserved

\section{Giris}

Tendon rüptürü vakaları, daha çok tendonların bağlantı yerleri olan, kemik ile birleşme noktası ya da kas tendon bileşkesinden meydana gelmektedir. Bunun sebebi de bu noktaların tendonların zayıf noktaları olmasıdır (Culver, 1976; Givissis ve ark., 2005). Ancak literatürde sadece altı, kapalı fleksör tendon rüptürü vakası mevcuttur (Culver, 1976; Givissis ve ark., 2005). Bu altı vakanın sadece üçü fleksör pollisis longus tendonuyla ilgilidir (Givissis ve ark., 2005). FPL tendonu anatomik ve fonksiyonel olarak birinci parmak için tek başına önemli bir yapı olarak karşımızda durmaktadır.
Tendonun birinci parmak amputasyonu olmadan ortaya çıktığ1 vakalar ise çok nadirdir (Takami ve ark., 1998). Literatürde FPL tendonunun amputasyon olmadan tenar bölgede açık yaralanmayla birlikte avülsiyonu sadece Givissis tarafindan 2005 yılında yayımlanmıştır.

$\mathrm{Bu}$ makalede tenar bölgede açık yaralanması olan, FPL tendonunun kas tendon bileşkesinden avülsiyonunun olduğu, oldukça ender görülen bir vaka incelenecektir. Yine ayırıcı bir özellik olarak tendon tamiri palmaris longus tendonuna transfer yoluyla yapılmıştır. İşlevsel sonuç, postoperatif ikinci ayda oldukça memnun edicidir. 


\section{Olgu}

Acil servise başvuran yirmi beş yaşındaki bayan hasta, sağ el tenar bölgede distal pediküllü flep şeklinde cilt kesisi, birinci parmağını bükememe ve parmakta his kaybı şikayetleri nedeniyle değerlendirildi. Yaralanma, hastanın ağır bir çuvala sağ eli ile asılırken çuvalın bağlı olduğu halatın çengel şeklindeki kısmının tenar bölgeden eline girmesiyle oluşmuştu. İlk muayenede hastanın birinci parmağında total fleksiyon kaybı, kas tendon bileşkesinden avülse olmuş bir FPL tendo$\mathrm{nu}$, tenar bölgede yaklaşık $4 \mathrm{~cm}$ distal pediküllü flep tarzında cilt kesisi ve kısmen his kaybı semptomlarının mevcut olduğu tespit edildi. Parmakta dolaşım muayenesi normaldi. Bu bulgularla hasta kliniğimize yatırıldı. Gerekli ön hazırlıkları takiben, bilgilendirilmiş hasta onayı da alınarak operasyona alındı. Operasyon sedasyon anestezisi ve ek olarak lokal anestezi altında gerçekleştirildi. Kansız bir ortamda çalışmak için hastanın sağ koluna esmarc bandajı uygulandı. Yapılan eksplorasyonda birinci parmağın FPL tendonunun proksimal kas tendon bileşkesinden avülse olduğu gözlendi (Şek. 1).

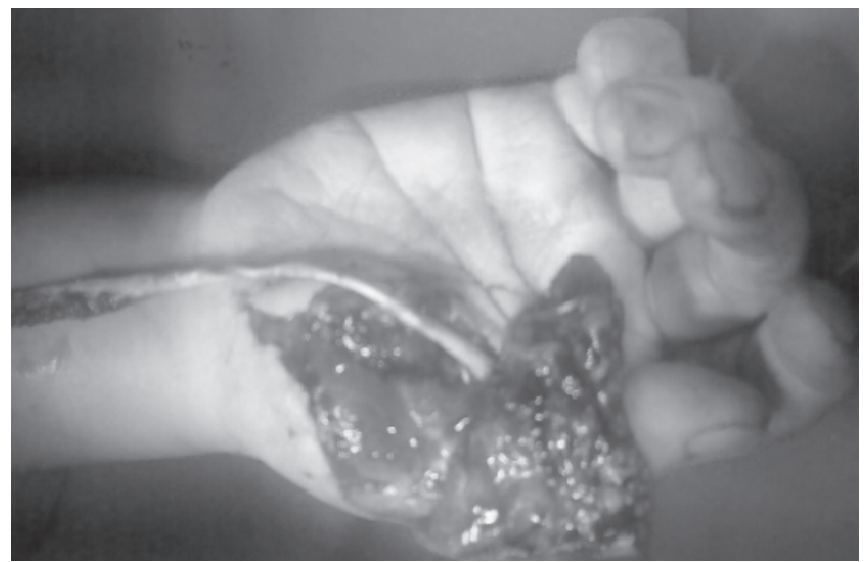

Şek. 1. Yaralanmadan sonra preoperatif görünüm; tenar bölgede distal pediküllü flep tarzında kesi ile birlikte fleksör pollisis longus tendonunun avülse olduğu görülmektedir.

FPL tendonunun avülse kısmı kısmen eksize edildikten sonra tendonun proksimal ve distal uçları arasında defekt kaldığından ve kas tendon bileşkesine ulaşabilmek için daha çok diseksiyon yapmak gerekeceğinden, primer tamir uygun bir yöntem olarak görülmedi. Bu nedenle FPL tendonu palmaris longus tendonuna transfer edilerek rekonstrükte edildi. (Şek. 2).
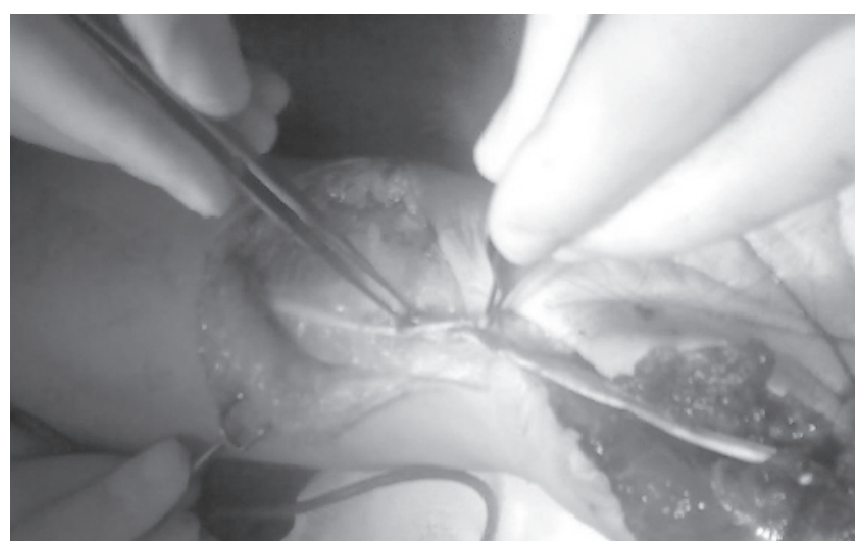

Şek. 2. Fleksör pollisis longus tendonunun fleksör palmaris longusa transferi ile rekonstrüksiyonu; tendon koaptasyonu fleksör pollicis longus tendonu karpal tünelden geçirildikten sonra yapılmıştır.
$\mathrm{Bu}$ onarım tendon karpal tünelden geçirildikten sonra yapıldı ve böylece ek bir pulley oluşturma girişimine gerek duyulmadı. Cilt primer kapatıld1. Postoperatif takiplerde geliştiği görülen cilt nekrozu sınırlarının belirginleşmesinin ardından, bu bölgeye ikinci bir operasyonla debridman ve kısmi kalınlıkta cilt grefti uygulandı. Postoperatif ikinci ayda fonksiyonel ve yara iyileşmesi açısından sonuç, oldukça memnun edici idi (Şek. 3,4).

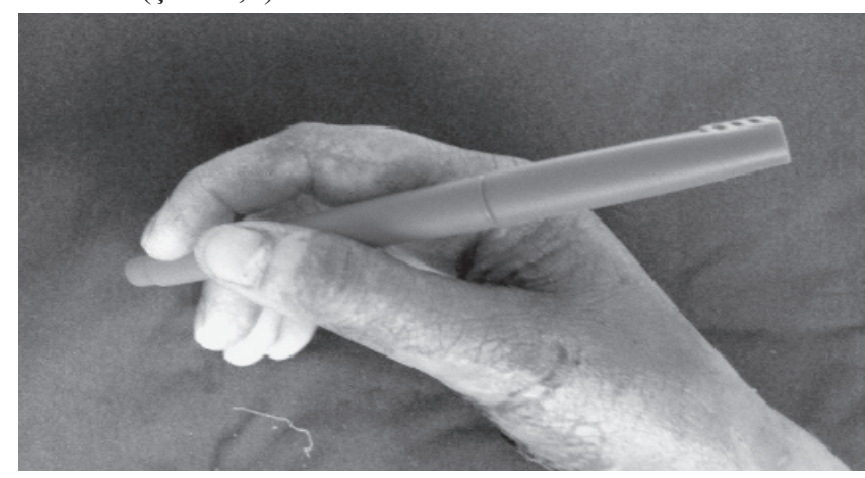

Şek. 3. Postoperatif 2. aydaki görünüm; hasta aynı eli ile bir kalemi tutabiliyor.

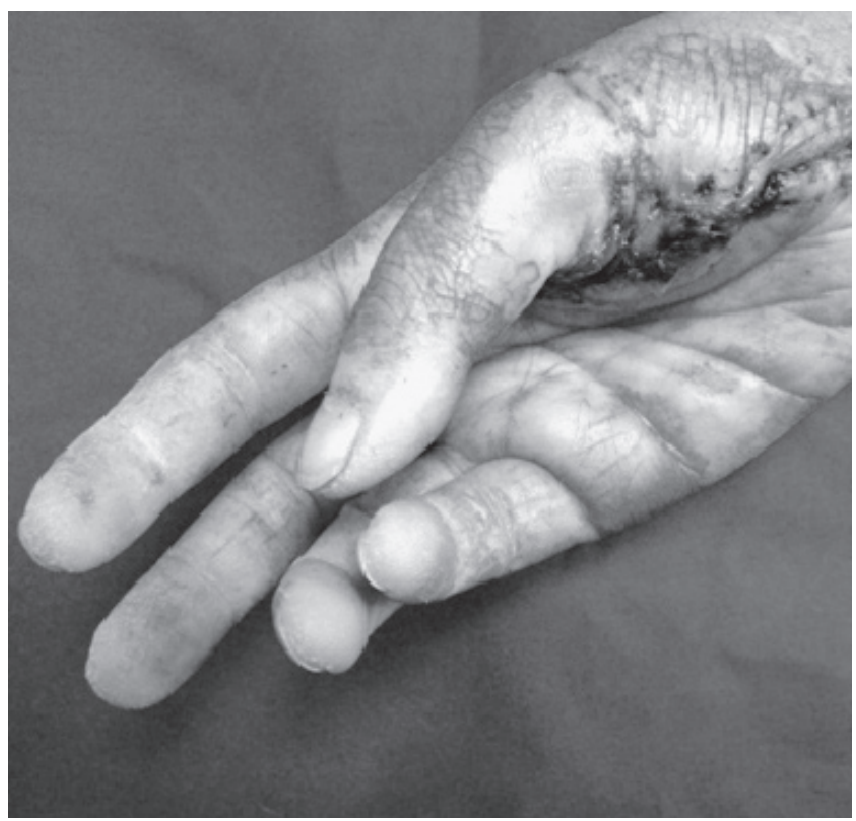

Şek. 4. Postoperatif 2. ay

\section{Tartışma}

Fleksör tendonların travmaya bağlı rüptürü çok nadirdir (Culver, 1976; Takami ve ark., 1998; Givissis ve ark., 2005). Genelde de kas kemik bileşke noktasından olmaktadır. Bunun nedeni kas tendon bileşkesi ve kas kemik bileşkesinin tendonların zayıf noktaları olmasıdır (Takami ve ark., 1998). Buna rağmen kas tendon bileşkesinden kopma vakaları oldukça nadir olarak karşımıza çıkmaktadır. Literatürdeki diğer vakaların daha çok, belki de batı toplumlarının bir alışkanlığ olmasından, bowling oyunu gibi bazı sportif aktiviteler sırasında ortaya çıktığı gözlenmektedir. Fleksör tedonların kapalı rüptürüne dair literatürde yalnızca altı vaka mevcuttur (Givissis ve ark., 2005). Bu vakaların ise sadece üçü FPL ile ilgili olup bunların da yalnızca birinde açık yaralanma mevcuttur. Bizim vakamız bu açıdan literatürde yayınlanmış ikinci vaka olma özelliği ile de önem arz etmektedir. Literatürde trav- 
matik parmak amputasyonunu da içeren fleksör tendonların kas tendon bileşkesinden avülse olduğu yayınlar mevcuttur (Givissis ve ark., 2005). Bununla ilgili ilk vaka ise 1929'da Adams tarafından yayınlanmıştır (Takami ve ark., 1998). 1960 yılında Boyes ve arkadaşları yetmiş sekiz hastayı içeren tendon rüptürü vakalarını yayınlamışlardır (Takami ve ark., 1998). Bu çalışmada vakaların büyük çoğunluğu ekstansör tendonlarla ilgili olup sadece dört hastada fleksör tendon rüptürü kas tendon bileşkesi düzeyindedir. Fleksör digitorum süperfisialis izole travmatik avülsiyonunu içeren bir başka çalışmada, gerek derin gerekse yüzeyel fleksör tendon yaralanmalarının kas kontraksiyonlarına karşı bir kuvvet uygulanması yoluyla ortaya çıktığı belirtilmiştir (Schnebel ve ark., 1989). Boyes ve arkadaşlarının çalışmasında sadece iki izole yüzeyel fleksör tendon rüptürü vakası yayınlanmış olup mekanizma aynıdır. Literatürdeki diğer çalışmalarda olduğu gibi ortak neden, fleksör tendonun kasılmasına karşı daha büyük bir kuvvet uygulanması ve sonuç olarak tendonun zayıf noktaları olan kemik ya da kas bileşkesinden kopmasıdır.

Tung ve ark., (1997) tek vakalık bir yayınında FPL tendon rüptürü olan bir hastada onarım, tendonun uzatılması yoluyla sağlanmıştır. Çalışmadaki vaka yaklaşık bir senelik bir vaka olup, FPL tendonuna $\mathrm{Z}$ plasti ile uzatma yapılarak rekonstrüksiyon uygulanmıştır. Bu çalışmada FPL rüptürünün tendon kemik bileşkesinden rüptürü tartışılmış olup, bu tür vakaların en az yapılan rekonstrüksiyon yöntemi kadar ender görüldüğü vurgulanmıştır.

Takami ve ark.'nın bir başka çalışmasında on ekstansör tendon rüptürü vakası sunulmuştur (Takami ve ark., 1997). Vakaların üçü tendon transferi yoluyla tamir edilirken, diğer vakalar uç uca ya da yan yana sütüre edilerek onarılmıştır. Literatürdeki diğer yayınlarda olduğu gibi bu yayında da tendon rüptürü vakalarının genelde sportif aktivite sırasında meydana geldiği belirtilmiştir. Diğer sebepler olarak distal radius k1rıkları ve romatoid artrit belirtilmiştir (Takami ve ark., 1997). Ancak tüm vakalarda tendona uygulanan ani traksiyon sebep olarak gösterilmiştir. Travmatik tendon rüptürü ise daha nadir bir durum olduğu vurgulanmıştır. Diğer tendon rüptürlerinde olduğu gibi ekstansör pollisis longus tendon rüptürü de ge- nelde romatoid artrit ve distal radius kırıklarını takiben ortaya çıkmaktadır (Takami ve ark., 1997; Uemura ve ark., 2008). Sportif aktivite sırasında rüptür vakaları ise nadir değildir.

Ahmad ve ark.'nın bir çalışmasında fleksör tendon yaralanmalarının en yaygın el yaralanması şeklinde olduğu belirtilmiştir (Ahmad ve ark., 2007). Otuz üç vakayı içeren bu çalışmada FPL tendon avülsiyonu sadece bir vakada gözlenmiştir. Aynı çalışmada yüzeyel fleksör tendon avülsiyonu sayıs1 ise yine birdir. Bu çalışmada fleksör tendonların zon 1-5 arasındaki çeşitli onarım metotları ve takibi tartışılmış olup avülsiyon yaralanmalarına değinilmemiştir.

Bu geniş sayıda vakayı içeren çalışmada görüldüğü gibi FPL avülsiyonu oldukça ender bir şekilde karşımıza çıkmakta ve genelde bu tarz travmatik tendon yaralanmaları distal radius kırıklarının bir komplikasyonu olabilmektedir (Klug ve ark., 2007).

El yaralanmalarını anlayabilmek ve doğru tedavi planı yapabilmek için elin anatomisine, biyomekaniğine ve fizyolojisine hakim olmak gerekmektedir (Bilgin ve ark., 2008). Literatürde ekstansör tendon avülsiyon yaralanmaları oldukça yaygın olup fleksör tendon avülsiyon vakaları daha nadir olarak karşımıza çıkmaktadır. Ekstansör tendon anatomisi oldukça komplike olmasına rağmen, yaralanmaları genellikle hafife alınmaktadır. Yaralanmaya göre splint tedavisinden, primer tamir ve rekonstrüktif girişimlere kadar değişen tedavi seçenekleri mevcuttur. Fleksör tendonlar anatomik lokalizasyonları ve fonksiyonları gereğiyle kompleks yapılardır ve tedavilerinde uygun cerrahi teknik ve rehabilitasyon anahtar rol oynar. Altta yatan farklı sebeplere bağlı olarak meydana gelmiş tendon rüptürlerine dair farklı metotlarla onarım teknikleri mevcuttur. Nedenler genelde çeşitli sportif aktiviteler, distal radius kırıkları ve romatoid artrit gibi inflamatuar hastalıklardır. Bu çalışmada daha önce literatürde bir kez yayınlanmış olan, tenar bölgede açık yaralanmalı FPL tendon avülsiyonu vakası sunulmuştur. Ayrıca FPL rekonstrüksiyonunda primer onarım ve dördüncü parmak yüzeyel fleksör tendon transferi yöntemlerine alternatif olarak palmaris longus tendon transferi metodu ile de oldukça memnun edici fonksiyonel sonuçlar sağlanabileceği düşünülmektedir.

\section{KAYNAKLAR}

Ahmad, M., Hussain, S.S., Tariq, F., Rafiq, Z., Khan, M.I., Malik, S.A., 2007. Flexor tendon injuries of hand: experience at Pakistan institude of medical sciences, İslamabad, Pakistan. J. Ayub. Med. Coll. Abbottabad. 19, 6-9.

Bilgin, S.S., Armangil, M., 2008. Surgical treatment of the tendon and nerve Injuries in the Hand. Turkiye Klinikleri J. Med. Sci.1, $30-37$.

Culver, J.E. 1976. Flexor digitorum superficialis rupture: a case report. Bull. Hosp. Joint Dis. 37, 30-33.

Givissis, P., Karataglis, D., Christodoulou, A., Terzidis, I., Pournaras, J., 2005. Open traumatic avulsion of the flexor pollicis longus tendon from the musculotendinous area: a case report. J. Hand. Surg. Am. 30, 850-853.

Klug, R.A., Press, C.M., Gonzalez, M.H., 2007. Rupture of the flexor pollicis longus tendon after volar fixed-angle plating of a distal radius fracture: a case report. J. Hand. Surg. Am. 32, 984-988.

Schnebel, B.E., Flesher, D., Garcia-Moral, C.A., 1989. Isolated traumatic avulsion of the flexor digitorum sublimis. Am. J. Sport. Med.17, 692694.

Takami, H., Takahashi, S., Ando, M., Suzuki, K., 1995. Traumatic rupture of the extansor tendons at the musculotendinous junction. J. Hand. Surg. 20, 474-477.

Takami, H., Takahashi, S., Ando, M., Kabata, K., 1998. Rupture of the flexor pollicis longus tendon at the musculotendinous junction in a bowler. Arch. Orthop. Trauma. Surg. 117, 277-278.

Tung, T.C., Chen, H.C., Wei, F.C., Tsai, T.R., 1997. Step-wise lengthening for delayed repair of avulsion of the flexor pollicis longus. Br. J. Plast. Surg. 50, 651-653.

Uemura, T., Kazuki, K., Hashimoto, Y., Takaoka, K., 2008. Skiing-induced rupture of the extensor pollicis longus tendon: a report of three cases. Clin. J. Sport. Med. 18, 292-294. 